\title{
VERBUL ÎN MANUSCRISUL ROMANULUI POPULAR SANDIPA
}

\author{
GALACTION VEREBCEANU \\ Institutul de Filologie Română „B. P.-Hasdeu” al MEC
}

\begin{abstract}
Rezumat. Sunt descrise particularitățile morfologice ale verbului prezente în textul romanului popular Sandipa, manuscris românesc 824, copiat în 1798 în partea de nord a Moldovei istorice și actualmente păstrat la Biblioteca de Stat a Federației Ruse, Moscova. Se pune accent pe acele trăsături morfologice care reflectă tendința de evoluare a limbii române de la sfârșitul secolului al XVIII-lea.

Cuvinte-cheie: condițional, conjugare, conjunctiv, diateză, gerunziu, imperativ, imperfect, indicativ, infinitiv, mai-mult-ca-perfect, mod, participiu, perfect compus, perfect simplu persoană, supin, timp, viitor.
\end{abstract}

Abstract. The morphological peculiarities of the verb present in the text of the popular novel Sandipa are described, Romanian manuscript 824, copied in 1798 in the northern part of historical Moldavia and currently kept at the State Library of the Russian Federation, Moscow. Emphasis is placed on those morphological features that reflect the evolution trend of the Romanian language since the end of the 18th century.

Keywords conditional, conjugation, conjunctive, diathesis, gerund, imperative, imperfect, indicative, infinitive, more-than-perfect, mode, participle, perfect compound, perfect simple person, supine, time, future.

Articolul de față este o continuare a descrierii caracteristicilor morfologice ale părților de vorbire flexibile din textul scrierii populare anunțate în titlu (ms. rom. 824, datat în 1798 și păstrat la Biblioteca de Stat a Federației Ruse, Moscova) ${ }^{1}$. In centrul analizei va fi verbul, clasa de cuvinte cu cea mai bogată flexiune și bine reprezentată din punct de vedere numeric, verbul fiind întrecut doar de substantiv.

Conjugări. Trecerea verbelor de la o conjugare la alta este un fenomen morfologic caracteristic, într-o anumită privință, textului de care ne ocupăm, nu însă în așa măsură cum se întâlnește în cele mai vechi texte românești (vezi Densusianu, 1961, p. 126-128; Rosetti, 1978, p. 559; ILRL, 1997, p. 131-133). Astfel, verbul a adăoga, prin cele două atestări consemnate în același context, aparține atât conjugării $\mathrm{I}^{2}$ : , pohtem cu tot gândul mieu să-m arăte şi să -m adaogă învăţătura" $\left(92^{v}\right)$, cât și conjugării a IV-a: ,să adăoge dor peste dor" $\left(92^{\mathrm{v}}\right)$.

${ }^{1}$ Vezi „Philologia”. 2021, nr. 1-2, p. 75-84.

$2 \mathrm{Ne}$ conducem de clasificarea etimologizantă a verbelor făcută de gramaticile tradiţionale. Despre alte clasificări, vezi bibliografia din GALR, I, 2005, p. 711. 
Tot forme duble se atestă în cazul lui a curge, care este de conjugarea I: „că-i cură lacrămile” $\left(37^{\mathrm{r}}\right)$, ,din buzile ei cură dulceață” $\left(38^{v}\right)$, ,toate gârlele câte cură în mare" (89v-2) și, o dată, de conjugarea a III-a, cu g analogic: ,şi-i curge lacrimile" $\left(36^{v}\right)$.

Verbul a scrie, prin cele două forme de imperfect: scriia $\left(14^{\mathrm{r}}, 62^{\mathrm{r}}\right)$, este de conjugarea a IV-a.

Verbele de conjugarea a IV-a a omorî și a urî conservă forma cu infinitivul în $-i$ : să omoari $\left(69^{v}\right)$, va uri $\left(12^{v}\right)$, să urescu $\left(92^{r}\right)$, singurele care înregistrează forme arhaice, mult mai numeroase fiind însă exemplele cu terminația în $-\hat{\imath}$ : omorî $\left(43^{\mathrm{v}}-2,53^{\mathrm{r}}, 55^{\mathrm{r}}\right)$ etc., borî $\left(75^{\mathrm{v}}\right), s-a$ hotărî $\left(94^{\mathrm{v}}\right)$, pârî $\left(15^{\mathrm{v}}, 69^{\mathrm{v}}\right)$ etc. Tendința de folosire a verbelor din subclasa în $-\hat{\imath}$ în dauna celor cu dezinenta în - $i$ caracterizează textele elaborate în a doua jumătate a secolului al XVIII-lea (vezi, de exemplu, ILRL, 1997, p. 334).

Diateze. Anumite verbe apar în pozitie dublă, fie reflexive, fie lipsite de se: te biruiești $\left(35^{\vee}\right)$, te biruiș $\left(59^{\vee}\right)$ - voi birui $\left(31^{\mathrm{r}}\right)$ etc., mă făgăduiesc $(u)\left(2^{\mathrm{v}}\right.$ 2), s-au făgăduit $\left(6^{\mathrm{r}}\right)$ - am făgăduit $\left(3^{\mathrm{r}}\right)$ etc., s-au greşit $\left(74^{\mathrm{r}}\right)$ - ai greşit $\left(87^{\mathrm{r}}\right)$, mă nădăjduiescu $\left(31^{\mathrm{r}}, 53^{\mathrm{r}}\right)$ - nădăjduiesc $\left(33^{\mathrm{r}}\right)$, ş-au râs $\left(41^{\mathrm{r}}\right)$ - râsă $\left(29^{\vee}\right)$, fie exclusiv la una dintre diateze, cum este cazul lui a bănui, care, prin singurul exemplu, este reflexiv: îş va bănui $\left(12^{v}\right)$. Fenomenul întrebuințării unuia și aceluiași verb în ambele ipostaze sau doar ca verbe reflexive se regăsește în toată perioada veche a limbii române (vezi Densusianu, 1961, p. 128-130; Rosetti, 1978, p. 559; ILRL, 1997, p. 133, 335).

Moduri personale. Inainte de a trece la examinarea modurilor predicative, să analizăm manifestarea unor verbe întâlnită la câteva moduri personale și forme verbale nepersonale. E vorba de fenomenul iotacizării, care este cauzat de actiunea modificatoare a iotului următor asupra consoanei finale din rădăcină, afectând verbele latine de conjugările a II-a, a III-a și a IV-a cu tema terminată în $d, n, t$ și uneori în $r$. Această transformare apare la indicativ prezent persoana 1 singular, la conjunctiv prezent persoana 1 singular și persoana a 3-a singular și plural și la gerunziu. Mai târziu, , $d, n$ și $t$ au fost refăcuți, prin analogie cu acele forme ale paradigmei care păstrează consoana originară" (Gheție, 1975, p. 166). Formele iotacizate curente în textele vechi (vezi Densusianu, 1961, p. 132-133; ILRL, 1997, p. 133-134, 335), apar frecvent și în manuscrisul Sandipa: să arză (58), să se ascunză $\left(25^{\vee}\right)$, nu te auz $\left(67^{\mathrm{r}}\right)$, să auz $\breve{a}\left(7^{\mathrm{r}}, 36^{\mathrm{r}}, 72^{\mathrm{r}}, 96^{\mathrm{v}}\right)$, să caz $\left(56^{\mathrm{v}}\right)$, să cază $\left(26^{\mathrm{v}}, 42^{\mathrm{r}}\right)$, să crează $\left(16^{\vee}\right)$, сеiu $\left(14^{\mathrm{V}}\right)$, să deșchiză $\left(95^{\vee}\right)$, să pociu $\left(28^{\vee}, 33^{\mathrm{V}}\right)$, să prinză $\left(64^{\vee}, 65^{\vee}\right)$, să pui $\left(82^{\mathrm{v}}\right)$, să puie $\left(76^{\mathrm{r}}, 90^{\mathrm{r}}, 96^{\mathrm{r}}\right)$, să purceg $\left(45^{\mathrm{v}}\right)$, să rămâie $\left(2^{\mathrm{v}}, 5^{\mathrm{v}}, 19^{\mathrm{v}}, 54^{\mathrm{r}}, 73^{\mathrm{v}}\right.$, $\left.85^{\vee}\right)$, să răspunză $\left(93^{\vee}\right)$, să sai $\left(58^{\mathrm{r}}\right)$, să saie $\left(58^{\mathrm{r}}\right)$, să scoață $\left(20^{\mathrm{v}}\right)$, să spui $\left(24^{\mathrm{r}}\right)$, să spuiu $\left(37^{\mathrm{v}}, 43^{\mathrm{r}}, 70^{\mathrm{r}}\right)$, să spuie $\left(31^{\mathrm{v}}, 81^{\mathrm{v}}\right)$, spuind $\left(47^{\mathrm{v}}\right)$, nespuindu $\left(40^{\mathrm{r}}\right)$, să $n u$ şazi (pers. a 3-a, 61 $)$, țiind $\left(31^{\mathrm{r}}\right)$, țiindu $\left(25^{\mathrm{r}}-2,31^{\mathrm{r}}\right)$, văz $\left(2^{\mathrm{r}}, 34^{\mathrm{r}}\right)$, văzu $\left(39^{\mathrm{r}}\right)$, s $\breve{a}$ văz $\left(18^{\mathrm{v}}, 31^{\mathrm{v}}, 39^{\mathrm{v}}, 63^{\mathrm{r}}\right)$, să vază $\left(24^{\mathrm{v}}, 25^{\mathrm{v}}, 30^{\mathrm{r}}, 36^{\mathrm{r}}, 52^{\mathrm{v}}, 55^{\mathrm{r}}\right)$, să $n u$ vazi $\left(46^{\mathrm{r}}\right)$, să vânză $\left(45^{\mathrm{v}}\right)$, viu $\left(62^{\mathrm{v}}\right)$, să vie $\left(16^{\mathrm{r}}, 35^{\mathrm{v}}, 38^{\mathrm{r}}, 53^{\mathrm{r}}, 72^{\mathrm{r}}, 74^{\mathrm{r}}, 81^{\mathrm{v}}\right)$, viind $\left(24^{\mathrm{r}}, 24^{\mathrm{v}}, 55^{\mathrm{r}}\right.$, $\left.69^{\mathrm{v}}, 75^{\mathrm{v}}, 80^{\mathrm{r}}, 92^{\mathrm{v}}\right)$.

Formele iotacizate nu sunt singurele întrebuintate, cele cu dentala refăcută, deși mai puțin numeroase, apar la câteva verbe: $(n u) \operatorname{pot}\left(33^{\mathrm{r}}, 60^{\mathrm{r}}\right.$, $88^{\mathrm{r}}-2,96^{\mathrm{r}}$ etc. $)$, să pot $\left(93^{\mathrm{v}}\right)$, să scot $\left(93^{\mathrm{v}}\right)$, să scoată $\left(58^{\mathrm{v}}-2,90^{\mathrm{r}}-2,96^{\mathrm{r}}-2\right)$, spun 
$\left(29^{\mathrm{r}}, 29^{\mathrm{v}}, 38^{\mathrm{v}}, 86^{\mathrm{r}}\right.$ etc. $)$, să spun $\left(13^{\mathrm{v}}, 44^{\mathrm{v}}, 78^{\mathrm{v}}, 97^{\mathrm{r}}\right.$ etc. $),(n u) \operatorname{tin}\left(31^{\mathrm{r}}, 41^{\mathrm{r}}, 49^{\mathrm{r}}\right)$, văd $\left(63^{v}, 85^{\mathrm{r}}\right)$.

Alt fenomen consemnat este apariția (sau lipsa) sufixului flexionar la unele verbe. Astfel, dintre cele 8 atestări ale verbului a trebui, doar o dată este consemnată forma sufixată: nu trebuieste $\left(96^{\mathrm{r}}\right)$. Forme slabe prezintă verbul $a$ birui: biruiescu $\left(51^{\mathrm{r}}, 86^{\mathrm{r}}\right)$, biruiești $\left(35^{\vee}\right)$, să biruiască $\left(40^{\vee}\right)$; cf. birui $\left(19^{\mathrm{r}}\right)$, voi birui $\left(31^{1}\right)$ etc., formele tari fiind mai numeroase. A păți este întrebuințat fără sufix: să nu paț $\left(35^{5}\right)$.

Indicativ prezent. Verbul neregulat a fi cunoaște puține forme gramaticale. La persoanele 1 singular și a 3 -a plural se constată forma sânt $\left(14^{\mathrm{r}}, 16^{\mathrm{v}}-2\right.$ etc.), concurată, în patru apariții, de sint $\left(2^{\mathrm{v}}, 27^{\mathrm{v}}, 53^{\mathrm{v}}, 56^{\mathrm{v}}\right)$, iar la persoana a 3-a singular, forma este $\left(17^{\mathrm{v}}\right.$ etc. $)$. Dintre formele scurte, consemnăm doar $-i:$, ,nu$i$ vina lui" ( $7^{\mathrm{v}}$ etc.).

Verbul a se ruga apare la persoana 1 singular sub forma inversată: rogu$m \breve{a}\left(14^{\mathrm{r}}, 29^{\mathrm{v}}, 45^{\mathrm{v}}\right)$, forma cu cliticul pronominal în prepoziție fiind mult mai numeroasă: $m a ̆$ rog $\left(15^{\mathrm{v}}, 22^{\mathrm{v}}, 44^{\mathrm{v}}\right.$ etc. $)$.

Imperfectul cunoaște, pentru persoana 1 singular, doar forme cu desinența $-m$ : căutam $\left(101^{v}\right)$, lepădam $\left(23^{\mathrm{r}}\right)$, vărsam $\left(92^{v}\right)$ etc., inovația aparținând textelor elaborate în Muntenia, de unde se răspândește în celelalte regiuni istorice (vezi Frâncu, 1971, p. 180-185; Gheție, 1972, p. 59-61; ILRL, 1997, p. 337). Persoana a 3-a plural prezintă însă numai forme etimologice, fără $-u$ analogic: aștepta $\left(81^{\mathrm{v}}, 95^{\mathrm{v}}\right)$, căde $\left(41^{\mathrm{v}}\right)$, chema $\left(81^{\mathrm{v}}\right)$, era $\left(3^{\mathrm{v}}, 4^{\mathrm{r}}, 35^{\mathrm{v}}, 56^{\mathrm{r}}, 63^{\mathrm{v}}, 78^{\mathrm{v}}, 84^{\mathrm{v}}, 89^{\mathrm{v}}\right)$, mânca $\left(75^{\mathrm{r}}\right)$, să mera $\left(7^{\mathrm{r}}\right)$, şide $\left(75^{\mathrm{r}}\right)$, trăia $\left(35^{\mathrm{v}}, 40^{\mathrm{v}}, 49^{\mathrm{v}}\right)$, situație caracteristică textelor din secolul al XVI-lea (vezi Rosetti, 1978, p. 561) și celor contemporane cu Sandipa (vezi ILRL, 1997, p. 337).

Unicul verb care înregistrează ambele forme este a sta: sta $\left(7^{\mathrm{r}}, 81^{\mathrm{v}}, 86^{\mathrm{v}}\right)$ $\sim \operatorname{stau}\left(79^{\mathrm{r}}, 81^{\mathrm{r}}\right)$, forma cu desinența analogică $-u$ fiind o inovație a graiurilor bănățene-hunedorene (vezi Gheție, 1975, p. 170).

Prin cele 11 atestări, verbul a sta nu cunoaște decât forme etimologice: sta (36 ${ }^{v}$ etc.; vezi și supra), forma reduplicată analogică cu perfectul simplu, stătea, fiind rarisimă în scrierile elaborate în secolele al XVI, al XVIII-lea (vezi ILRL, 1997, p. 337).

Câteva verbe de conjugarea a IV-a conservă terminația -ia: scriia $\left(14^{\mathrm{r}}\right.$, $\left.62^{\mathrm{r}}\right)$, știia $\left(92^{\mathrm{r}}\right)$; cf. însă grăia $\left(17^{\mathrm{r}}\right)$, sârguia $\left(74^{\mathrm{V}}\right)$, suduia $\left(25^{\mathrm{v}}, 63^{\mathrm{r}}\right)$, trăia $\left(35^{\mathrm{v}}\right.$, $\left.40^{v}, 49^{v}\right)$ sau terminația -ie: nu găsie $\left(31^{v}\right)$, trăie $\left(54^{v}\right)$.

Perfectul simplu, datorită aspectului narativ al textului, este întrebuințat frecvent, mai ales la persoana a 3-a. Bunăoară, din totalul de peste 300 de exemple, verbului a zice îi revine 272 de apariții: zisă $\left(2^{\mathrm{r}}-3,29^{\mathrm{v}}-5\right.$ etc.). Sunt consemnate exemple de perfect și la alte persoane: adusăiu $\left(99^{v}\right)$, călcaiu $\left(71^{\vee}\right)$, grăiiu $\left(71^{\vee}\right)$, mă impluiu $\left(84^{\vee}\right)$, pățiiu $\left(67^{\vee}\right)$, mă spăimântaiu $\left(37^{\vee}\right)$, trimesăiu $\left(39^{v}\right)$ etc.; te biruiş $\left(59^{v}\right)$, dăruiș $\left(93^{r}\right)$, te giuraș $\left(64^{r}\right)$, poronciș $\left(59^{v}\right)$, sfätuiș $\left(96^{\vee}\right)$, te ținuș $\left(39^{v}\right)$, văzuș $\left(54^{\mathrm{r}}\right)$ etc.; să cerşu $\left(82^{\mathrm{r}}\right)$, făcu(ră) $\left(3^{\mathrm{v}}, 58^{\mathrm{r}}\right)$,

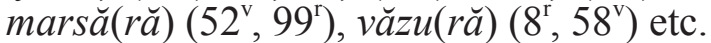

Verbul a fi prezintă numai forme asigmatice și doar la persoana a 3-a: $f u$ $\left(4^{\mathrm{v}}, 52^{\mathrm{v}}, 95^{\mathrm{r}}, 100^{\mathrm{r}}\right)$. 
Pentru persoana 1 plural norma textului este forma cu -ră analogic: adusără $\left(93^{\mathrm{r}}\right)$, agiunsără $\left(52^{\mathrm{r}}\right)$, căutară $\left(7^{\vee}\right)$, ruşinară $\left(96^{\mathrm{V}}\right)$ etc. Uneori însă -ră analogic apare, probabil din greșeală, și la persoana a 3-a singular: ,grăiră muiere” $\left(67^{\mathrm{r}}\right)$, ,purceasără bărbatul” $\left(35^{\vee}\right)$, ,o dusără la casa lui acel înşălătoriu" $\left(85^{\vee}\right)$ sau cu -ră lipsă: ,sezu oamenii la masă” $\left(62^{1}\right)$.

Unicul verb care atestă forme tari este $a$ da: dideiu $\left(48^{\mathrm{r}}\right)$, dede $\left(34^{\mathrm{r}}\right)$, dide ( $3^{v}$ etc.), dederă $\left(91^{v}\right)$, dediră $\left(78^{v}\right)$, fenomen răspândit în scrierile contemporane cu Sandipa (vezi ILRL, 1997, p. 339). Forma slabă de perfect a verbului $a$ da apare, o dată, la persoana a 2 singular: dideș $\left(35^{\mathrm{r}}\right)$ (despre istoria verbului $a$ da la perfectul simplu, vezi Frâncu, 1980, p. 307-314).

Perfectul compus se evidențiază prin similitudinea auxiliarului au de la persoana a 3-a singular cu persoana a 3-a plural, fenomen general în toate textele vechi (vezi Densusianu, 1961, p. 148; Rosetti, 1978, p. 563; ILRL, 1997, p. 138, 339; vezi, despre istoria fenomenului, Frâncu, 1973, p. 299318); ,Sandipa au dat zapis” (3 ), ,slujitoriul au ieşit şi au făcut precum 1-au învăţat muiere” $\left(25^{\mathrm{r}}\right),$, s-au născut fiiu filosofului” $\left(97^{\mathrm{v}}\right)$, ,, acum au venit numai doi" $\left(82^{v}\right)$. Forma cu $a$ la singular, inovație a graiurilor de sud (vezi Gheție, 1973, p. 421-430; Ghetie-Mareș, 1974, p. 248-251; Gheție, 1975, p. 171), este consemnată o dată: „Pricina este a omului carile a făcut masă mare” $\left(76^{r}\right)$ și ar putea fi explicată ca greșeală de copiere, întâlnită în textele din secolul al XVI-lea (vezi Densusianu, 1961, p. 143), sau ca reflex al limbii vorbite, care tolera, în unele graiuri, întrebuințarea lui $a$ atât la singular, cât şi la plural (vezi Frâncu, 1969, p. 299-318; Gheție, 1973, p. 421-430).

Referitor la topica auxiliarului, este de subliniat folosirea curentă a lui $a u$ în fața participiului, encliza auxiliarului fiind consemnată în gustat-au $\left(50^{1}\right)$ și făcut-au $\left(50^{\mathrm{r}}-2,50^{v}\right)$. Postpus participiului apare și auxiliarul de persoana a 2-a singular în: învătat-ai (4v), scris-ai $\left(88^{\mathrm{D}}\right)$ și, cu intercalarea cliticului pronominal, în ştiutu-le-ai $\left(68^{\natural}\right)$. Dacă nu e o greșeală a copistului, ai este exprimat dublu în exemplul ,i-ai dat-ai" $\left(88^{1}\right)$, construcție pleonastică în limba contemporană.

Expresia a-și aduce aminte are verbul plasat înaintea auxiliarului: Adusu-mi-am aminte $\left(28^{v}\right)$.

Mai-mult-ca-perfectul, în raport cu cele trei forme de trecut, apare rar și doar la persoana a 3-a singular: adusăsi $\left(66^{\vee}\right)$, aprinsăse (84 $)$, să ascunsăse $\left(7^{\vee}\right)$, auzisă $\left(91^{\mathrm{r}}\right)$, să împlusăse $\left(11^{\vee}\right)$, pusăsă $\left(9^{\mathrm{r}}\right)$, scrisăse $\left(68^{\vee}\right)$, zisăsi $\left(5^{\vee}\right)$ etc. Dintre construcțiile perifrastice, sunt de exemplificat au fost gătit $\left(1^{\mathrm{r}}, 96^{\mathrm{v}}\right)$ și au fost scăzut $\left(55^{\vee}\right)$, forme folosite uneori în textele de tip nordic (vezi ILRL, p. 339).

Viitorul apare întrebuințat cu forma nouă, construită, la fel ca în limba contemporană, cu ajutorul verbului a vrea + infinitiv: voi face $\left(38^{\mathrm{r}}\right)$, vei suspina $\left(44^{v}\right)$, va pohti $\left(88^{1}\right)$, vom priimi $\left(59^{\mathrm{r}}\right)$, vor trece $\left(72^{v}\right)$, net majoritară față de exemplele cu afereza lui v: oi face $\left(85^{\mathrm{r}}\right)$, or vre $\left(29^{\mathrm{r}}\right)$, ,dacă a însăra” $\left(87^{\vee}\right)$, „până a săca de tot" $\left(89^{v}\right)$, nu s-a ispiti $\left(16^{\mathrm{r}}\right), s-a$ săvârși $\left(31^{\mathrm{r}}\right)$ etc. și de cele cu forma scurtă a lui a vrea, persoana a 2-a singular: „ci- $i$ face” $\left(81^{v}\right)$, ,le- $i$ împăca” $\left(89^{v}\right)$, ,li-i birui” $\left(67^{1}\right)$, , ,i- $i$ omorî” $\left(40^{1}\right)$, ,li- $i$ pute faci” $\left(45^{\vee}\right)$, „,me$i$ face” $\left(63^{v}\right)$, ,mi- $i$ poronci” $\left(6^{\mathrm{r}}\right)$, ,mi- $i$ scoate” $\left(65^{\mathrm{v}}\right)$. In câteva exemple, se 
constată apariția auxiliarului în urma verbului de conjugat: da-ț-oi $\left(81^{v}\right)$, putevoi face $\left(34^{r}\right)$, spune-ţ-voi $\left(37^{1}\right)$.

Conjunctivul prezent nu se deosebește prin nimic de formele actuale: să fiu $\left(2^{v}\right)$, să afli $\left(21^{v}\right)$, să biruiască $\left(40^{v}\right)$, să părăsim $\left(50^{v}\right)$, să daţi $\left(75^{1}\right)$, să fie $\left(88^{v}\right)$ etc. Uneori conjunctivul are valoare imperativă: „De vei merge şi tu împ<r>eună cu dânsul, să meargă” $\left(27^{\mathrm{r}}\right)$, „Căţe să fii şi dulăii să umble după tine" $\left(37^{1}\right)$ etc.

Verbele neregulate $a$ bea a da și a lua apar la persoana 1 și a 3-a sub forme motivate fonetic: să beu $\left(89^{\mathrm{v}}-2\right)$, să be $\left(21^{\mathrm{v}}, 22^{\mathrm{r}}\right)$, să $(n u) d e\left(15^{\mathrm{v}}, 82^{\mathrm{v}}, 83^{\mathrm{r}}\right)$, să ie $\left(79^{\prime}\right)$. Verbul a avea prezintă la persoana 1 singular forma etimologică $s \breve{a}$ $\operatorname{aib}(u)\left(47^{\mathrm{r}}, 2^{\mathrm{v}}\right)$.

Conjunctivul perfect este consemnat în să fi apucat (11 $\left.{ }^{\mathrm{r}}\right)$, să fi legat $\left(8^{\mathrm{r}}\right)$, iar în unicul caz atestat auxiliarul a fi este variabil: ,să fie avut" (54').

Condiționalul prezent și condiționalul perfect apar foarte rar în text, iar exemplele nu se diferențiază de cele din limba de astăzi, auxiliarul fiind variabil și plasat numai în prepoziția verbului la infinitiv: aş ave $\left(81^{v}\right)$, ai ave $\left(21^{\vee}\right)$, ar cere $\left(85^{\vee}\right)$, am sfätui $\left(57^{\vee}\right)$, aş fi pitrecut $\left(46^{\vee}\right)$, ai fi văzut $\left(63^{\vee}\right)$, ar fi fost $\left(54^{\mathrm{r}}\right)$ etc.

Imperativul prezintă doar forme scurte, identice cu cele actuale: aşteaptă $\left(31^{v}\right)$, cereți $\left(83^{r}\right)$, grăiește $\left(94^{v}\right)$, mergi $\left(70^{r}\right)$, nu te grăbi $\left(35^{r}\right)$ etc.

La persoana a 2-a singular, verbele $a$ aduce și a sta conservă formele etimologice $a d u$ și stă: ,„Adu-1 aice în peşteră” $\left(28^{\prime}\right)$, ,stă , nu fugi” $\left(86^{\prime}\right)$, ,întră în casă şi te păzeşte să nu te cunoască şi stă între dânşii can deoparte" $\left(87^{\vee}\right)$, iar $a$ veni atestă forma analogică vino: ,Vino în dugheană” $\left(29^{v}\right)$, ,vino la casa me desară” $\left(47^{\mathrm{r}}\right)$, „Omule, vino să ne luptăm din cuvinte” $\left(86^{\mathrm{r}}\right)$.

Pentru câteva verbe se constată forme particulare de imperativ. Astfel, sinonimul verbului a merge este arhaicul blem $(<\hat{\imath}$ mblăm $<$ lat. ambuleus): „mare zarvă mi-ai făcut cu ace dulamă, ci blem să ţ-o dau” $\left(49^{v}\right)$, ,Blem în casă şi-m dă banii” $\left(79^{v}\right)$, care intră în alternanţă cu a merge: ,mergi la tatămieu şi-i spune toate câte ţ-am spus și mergi mai înainte până a nu merge ace muieri” $\left(70^{1}\right)$, ,mergit şi căutaţ pe celalant şi apoi mergiţ la muierea şi cereți banii" $\left(83^{\mathrm{r}}\right)$ și, într-un fel, cu interjecția verbală haide $(<$ tc. haide) „să mergem": „Haide să întrăm aice” $\left(28^{\mathrm{r}}\right)$. La fel învechită este și forma de imperativ pasă (< lat. passare) ,du-te, pleacă”: „Pasă dar acum într-un ceas bun şi mulţemeşte muierii mele” $\left(26^{\mathrm{r}}\right)$, ,Pasă acasă, fimeie” $\left(35^{\mathrm{r}}\right)$, ,Dumneta pasă iar acolo la dugheană" $\left(48^{\prime}\right)$, ,pasă acum de be toată apa mării” $\left(89^{1}\right)$.

În cazul verbelor reflexive, cliticul pronominal este plasat în fața verbului: mă aşteaptă" $\left(31^{\vee}\right)$, mă suduieşti $\left(25^{\mathrm{V}}\right)$, te amestică $\left(87^{\vee}\right)$, te fă $\left(25^{\mathrm{r}}\right)$, te gătește $\left(38^{\mathrm{r}}\right)$, te păzește $\left(87^{\vee}\right)$ etc. sau după verb: izbăvești-mă $\left(81^{\vee}\right)$, roagăte $\left(28^{v}\right)$, scoală-te $\left(38^{r}\right)$ etc. ori, pentru același verb, în prepoziția și postpoziția verbului: mă ascultă $\left(26^{\mathrm{v}}, 41^{\mathrm{v}}, 43^{\mathrm{r}}, 57^{\mathrm{r}}\right)$ - ascultă-mă $\left(82^{\mathrm{r}}\right), d u$-te $\left(45^{\mathrm{v}}, 69^{\mathrm{r}}, 79^{\mathrm{r}}\right)$ te $d u\left(87^{v}\right)$.

Prezumtivul trecut este reprezentat de unicul exemplu: „de va $f i$ şi indrăgit ea pe tânărul acista" (34v).

Formele verbale nepersonale. Infinitivul apare exclusiv sub formă scurtă și coincide întru totul cu cel din limba contemporană: a arăta (4), a grăi (36), 
a nevoi $\left(93^{\mathrm{v}}\right)$ etc. În relatie cu incoativul a incepe, infinitivul este preferat în dauna conjunctivului, înregistrând 35 de ocurențe: începu a bate $\left(39^{v}\right)$, va incepe a face $\left(97^{\vee}\right)$, începusă a pica $\left(18^{\vee}\right)$, au început a să ruga $\left(91^{\vee}\right)$ etc.

Gerunziul, în afară de faptul că folosește aceleași forme ca și azi, se caracterizează prin menținerea formelor iotacizate de felul spuind, țiind, viind (vezi supra). Verbul $a(n u)$ vedea are, în toate cele 25 de apariții, forma (ne) văzind $\left(2^{\mathrm{r}}, 48^{\mathrm{r}}\right.$ etc.), a vinde, forma vânzind $\left(50^{\mathrm{r}}\right)$, iar a ședea, forma şăzind $\left(5^{\mathrm{v}}, 93^{\mathrm{r}}\right)$.

Participiul verbului învechit a meșteșugui ,a meșteșugi” este meşteşuguit $\left(17^{\vee}\right)$, al regionalismului a se zăbăvi, zắbằvit $\left(24^{\vee}\right)$, iar a lui a zăuși ,a zăpăci”, zăuşit $\left(27^{\mathrm{v}}\right)$, în rest se constată forme moderne: auzit $\left(23^{\mathrm{v}}\right)$, făcut $\left(67^{\mathrm{r}}\right)$ etc.

Participiul verbelor a cerși și a sta nu este întrebuințat în text, dar, după forma de perfect simplu să cerşu $\left(82^{\mathrm{r}}\right)$, stătu $($ ră $)\left(59^{\mathrm{r}}-2,84^{\mathrm{r}}, 87^{\mathrm{V}}-2\right)$ și cea de gerunziu cerşind $\left(15^{\mathrm{v}}, 16^{\mathrm{r}}\right)$, este de presupus că participii de felul cerșut și stătut erau cunoscute în epocă (vezi, de exemplu, ILRL, 1997, p. 343).

Supinul nu se diferențiază de cel din limba de astăzi și selectează, de regulă, prepoziția de: ,au sfârşit ace cenuşă şi ţerna de mâncat” $\left(62^{r}\right)$, „ci fel de marfă ai și au de vândut este?” (84'), ,Şi nici este de vorbit”" (40v) sau, mai rar, altă prepoziție: ,Şi purceasă la vânat” $\left(27^{1}\right)$.

Rezumând descrierea trăsăturilor morfologice ale verbului înregistrate în textul manuscrisului romanului popular Sandipa, putem constata că această clasă de cuvinte prezintă o vădită tendință de simplificare și reducere a formelor arhaizante, favorizând întrebuințarea celor noi, ulterior acceptate de norma limbii literare actuale. Mai mult, inovațiile fac concurență formelor vechi, împingându-le la periferia sistemului: a cura, dar a curge, s-au făgăduit, însă am făgăduit, să scoață, dar să scoată, să fie avut, dar să fi apucat etc. Alteori, formele vechi continuă să se mențină în dauna formelor noi: să nu paţ pentru să nu pățești, era pentru erau, să aib pentru să am, stă pentru stai, pasă pentru du-te etc.

\section{Referințe bibliografice:}

1. DENSUSIANU, Ovid. Istoria limbii române. Vol. II. Secolul al XVI-lea. Ediție îngrijită de prof. univ. J. Byck. București, 1961.

2. FRÂNCU, Constantin. Formele de persoana a III-a ale auxiliarului de la perfectul compus. Privire istorică. În: „Studii și cercetări lingvistice”, XX, 1969, p. 299-318.

3. FRÂNCU, Constantin. Cu privire la vechimea a două inovații în flexiunea verbală comune dialectelor limbii române. În: „Fonetică și dialectologie”, VII, 1971, p. 180-185.

4. FRÂNCU, Constantin. Din istoria verbelor neregulate: perfectul simplu şi mai mult ca perfectul a da și a sta. În: „Limba română”, XXIX, 1980, nr. 4, p. 307-314.

5. GALR = Gramatica limbii române. I. Cuvântul. București, 2005.

6. GHET⿱IE, Ion. Vechimea formelor verbale in $-m$ de la pers. $1 \mathrm{sg}$. a imperfectului. În: „Studii și cercetări lingvistice”, XXIII, 1972, nr. 1, p. 59-61. 
7. GHEȚIE, Ion. Originea auxiliarului a de la pers. 3 sg. a perfectului compus. În: „Studii și cercetări lingvistice”, XXIV, 1973, nr. 4, p. 421-430.

8. GHEȚIE, Ion. Baza dialectală a românei literare. București, 1975.

9. GHEȚIE, Ion, MAREȘ, Al. Graiurile dacoromâne în secolul al XVI-lea., București, 1974.

10. ILRL = Academia Română. Institutul de Lingvistică "Iorgu Iordan” București. Istoria limbii române literare. Epoca veche (1532-1780) de Gheorghe Chivu, Mariana Costinescu, Constantin Frâncu, Ion Gheţie, Alexandra Roman Moraru şi Mirela Teodorescu. Coordonator Ion Gheţie. București, 1997.

11. ROSETTI, Al. Istoria limbii române. 1. De la origini pînă la începutul secolului al XVII-lea. Ediție definitivă. București, 1978.

Notă: Articolul a fost realizat în cadrul proiectului de cercetare 20.80009.1606.01 Valorificarea științifică a patrimoniului lingvistic național în contextul integrării europene, Institutul de Filologie Română „B. P.-Hasdeu” al MECC. 